\title{
Relationship between severity of trunk decay of Pinus koraiensis and soil properties around roots
}

\author{
Huadong $\mathrm{Xu}^{1} \cdot$ Wenjing Chen ${ }^{1} \cdot{\text { Yanjun } \mathrm{Cao}^{1}}^{1}$ \\ Lihai Wang ${ }^{1}$
}

Received: 24 July 2019 / Accepted: 1 December 2019 / Published online: 3 June 2020

(C) The Author(s) 2020

\begin{abstract}
The decay rate of standing Korean pine (Pinus koraiensis) in natural forests can be as high as $50 \%$ and is likely influenced by the soil properties and nutrient and water status of the site. To clarify the relationship between the severity of tree decay and soil properties in order to prevent decay in a natural mixed forest in the Xiaoxing' an Mountains, wood strength of standing trees was nondestructively assessed, and the severity of decay of extracted wood cores was quantified based on differences in mass between two decayed increment cores extracted at breast height and an intact increment core near the decayed ones. Soil samples from the critical root zone (non-rhizosphere) of each tree were analyzed for chemical properties and microbial composition. The abundance of chemical elements (especially total $\mathrm{N}$ and $\mathrm{K}$ ) and the species richness of soil microbes increased as decay severity increased. Fungal number (FN) and actinomycetes number (AN) were related to decay severity $\left(R^{2}=0.504\right)$. Bacterial number $(\mathrm{BN})$ was higher than $\mathrm{FN}$ or AN, but had a minor effect on tree decay. Path analysis showed BN might indirectly inhibit decay by affecting FN.
\end{abstract}

Project funding: This work was financially supported by the National Natural Science Foundation of China (Grant Nos. 31870537 and 31570547), the Fundamental Research Funds for the Central Universities of China (Grant No. 2572018BL08), and the Research and Development Project of Application Technology in Harbin (Grant No. 2017RAQXJ078).

The online version is available at http://www.springerlink.com.

Corresponding editor: Yu Lei.

Huadong Xu

huadongxu@yahoo.com

1 College of Engineering and Technology, Northeast Forestry University, Harbin 150040, People's Republic of China
Decay severity was not significantly correlated with either soil fungal or bacterial diversity. These results suggest that forest managers need to monitor levels of fungi and total $\mathrm{N}$ and total $\mathrm{K}$ levels to reduce the decay of Korean pine.

Keywords Pinus koraiensis - Soil chemical properties . Soil microbial properties $\cdot$ Trunk decay degree

\section{Introduction}

Korean pine (Pinus koraiensis Siebold \& Zucc.), one of the dominant tree species in natural forests of the Xiaoxing'an Mountains in North China, is irreplaceable for providing structural stability to local forest ecosystems. Its wood is prized for its high quality and strength and easy processability (Lv and Qu 2010). However, wood decay of Pinus koraiensis in natural forests has become a serious problem (Li et al. 2014; Wang et al. 2015). Tree decay is an essential biological process that produces carbon dioxide and water with a release of energy to maintain forest processes (Bednarz et al. 2013), but wood quality is diminished by wood rot fungi during the decay process (Shortle and Dudzik 2012). Such decay affects tree health and timber production by degrading wood cell walls and reducing wood mechanical and physical properties. Factors such as forest density, site conditions (e.g., elevation, slope, humidity, temperature, light, and soil), hydrology and human and animal activities (Chen 1959) need to be assessed for their contributions to tree decay and loss so that appropriate management strategies can be designed.

Among the site conditions, soil properties are critical to the availability and absorption of water and nutrients by trees and affect the rhizosphere of standing trees and thus influence tree decay, as shown by our previous studies on 
soil physicochemical properties in relation to tree decay (Sun et al 2015). We found that enhanced $\mathrm{C} / \mathrm{N}$ ratios and $\mathrm{pH}$ in the soil of the root zone was associated with more decay in Korean pine trunks. Hietala et al. (2016) noted that the incidence of decay in Norway spruce also increased as the $\mathrm{pH}$ increased from 3.8 to 6.4. These studies indicate a close relationship between tree decay and soil chemical properties.

These properties in turn are closely related to soil microbial communities (Hu et al. 2006; Martiny et al. 2006; Pietri and Brookes 2008); the abundance and composition of the communities can influence soil chemical properties, which can then affect chemical composition (Cai and Huang 2016). In addition, soil microbes can infect roots which could eventually cause trunk decay. However, little information is available on direct relationships between tree decay and soil microbial properties and how soil microbial quantity and diversity contribute to the incidence and severity of decay. Such information is critical to control tree decay; when the relationships are clearer, management practices can be designed to adjust soil properties to improve forest soil and reduce decay in Korean pine.

Therefore, the objective of this study was to analyze the relationship between the degree of tree decay and soil microbial properties based on our previous research and the effects of soil chemical and microbial properties on decay severity in standing trees of Pinus koraiensis. This basic data will lead to the development of forest management practices that reduce decay in this important species.

\section{Materials and methods}

\section{Study area}

The study area in northeastern China is located in the Liangshui National Nature Reserve on the southern slope of the Dailing region, the largest branch of the Xiaoxing' an Mountains. It has a cold continental monsoon climate with an annual average temperature of $1.4{ }^{\circ} \mathrm{C}$. Field tests and surveys of Pinus koraiensis were carried out in a 30-ha sample plot in the 18th block of the Liangshui Forest District. The main soil type is dark brown forest soil; the dominant tree species is Pinus koraiensis accompanied by species such as Ulmus pumilaTrautv., Abies fabri, Betula costata Trautv., and Tilia tuan Szyszyl.

\section{Determination of tree decay severity}

In the 18th block, the sample plot was divided into 750 quadrats, each $20 \mathrm{~m} \times 20 \mathrm{~m}$, and 100 quadrats containing $P$. koraensis were then selected along an S-shaped transect in the plot. For ensuring the selected tree types were distributed over a wider area, no more than three trees were tested in each quadrat. A total of 200 trees were visually observed for decay symptoms and the internal physical structure of the wood tested using 2D stress wave tomography (Arbotom, Rinntech, Heidelberg, Germany) and a Resistograph (model 4453, Rinntech) according to the manufacturer's instructions. Based on the nondestructive test results, nine trees with decay and one healthy $P$. koraensis trees were chosen as sample trees, each in a different quadrat. For each sample tree, two decaying increment cores were extracted at breast height, and an intact core extracted near the decaying ones. Each wood core was oven-dried $\left(105^{\circ} \mathrm{C}\right)$ to a constant mass and weighed. The mass of the decayed wood cores $\left(m_{1}\right)$ and intact wood cores $\left(m_{2}\right)$ were used to calculate the loss in mass of wood cores $(S)$ as $S=\left[\left(m_{2}-m_{1}\right) / m_{2}\right] \times 100$ (Liu et al. (2015) to describe the severity of tree decay.

\section{Soil chemical properties measurement}

Soil samples of $500 \mathrm{~g}$ were collected from four sampling sites in the critical root zone (rhizosphere) of the selected trees. Surface vegetation, branches and leaves were removed before drilling with an auger to obtain samples from the A horizon at 6-20 $\mathrm{cm}$ depth. The 44 soil samples were placed in a sterile bag, which was sealed and taken immediately to the laboratory. Half of the samples were used for chemical analyses, and the other half for microbe isolations and stored at $-20{ }^{\circ} \mathrm{C}$ until used.

For chemical analyses, soil samples were air-dried, screened with a $2 \mathrm{~mm}$ mesh, and fine roots removed. Total and hydrolyzed $\mathrm{N}$, total and available $\mathrm{P}$, total and available $\mathrm{K}$ contents were determined according to forest industry standards in China (LY). Total $\mathrm{N}$ was measured using the Kjeldahl method (LY/T 1228-1999). Total K was tested using acid dissolution-flame photometry (LY/T 1234-1999). Total $\mathrm{P}$ was measured using anti-colorimetric determination of acid-soluble molybdenum and antimony (LY/T1232-1999). Hydrolyzed $\mathrm{N}$ was measured using alkali hydrolysis diffusion (LY/T 1231-1999). Available K was extracted using ammonium acetate-flame photometry (LY/T 1236-1999). Available $\mathrm{P}$ was tested using the anti-colorimetric method and molybdenum and antimony with sodium hydroxide extraction (LY/T 1233-1999).

\section{Soil microbial isolation and quantification}

From each fresh soil sample, $1 \mathrm{~g}$ was diluted to $10^{-2}-10^{-7}$ with distilled water and shaken 15-20 min. Each dish of medium received $0.05 \mathrm{~mL}$ of the $10^{-5}$ to $10^{-7}$ dilutions to plate bacteria on beef extract peptone, $10^{-3}$ to $10^{-5}$ for fungi on Martin's medium and $10^{-2}$ to $10^{-4}$ for actinomycetes on Gaoshi No. 1 medium (Table 1; Xu et al. 2019). Each concentration was plated out on three dishes. 
Table 1 Composition of media to isolate bacteria, fungi and actinomycetes from soil

\begin{tabular}{|c|c|c|c|}
\hline Type & Composition & Mass $(\mathrm{g})$ & Volume (mL) \\
\hline \multirow[t]{7}{*}{ Martin's medium for funigi } & $\mathrm{KH}_{2} \mathrm{PO}_{4}$ & 1.0 & \\
\hline & Glucose & 10.0 & \\
\hline & Agar powder & 15.0 & \\
\hline & $\mathrm{MgSO}_{4} \cdot 7 \mathrm{H}_{2} \mathrm{O}$ & 0.5 & \\
\hline & Peptone & 5.0 & \\
\hline & $1 / 3000$ Bengal red solution & & 100 \\
\hline & distilled water & & 900 \\
\hline \multirow[t]{5}{*}{ Beef extract peptone medium for bacteria } & Beef extract & 3.0 & \\
\hline & Peptone & 10.0 & \\
\hline & Agar & 15.0 & \\
\hline & $\mathrm{NaCl}$ & 5.0 & \\
\hline & Distilled water & & 1000 \\
\hline \multirow[t]{8}{*}{ Gaoshi no. 1 medium for actinomycetes } & Soluble starch & 20.0 & \\
\hline & $\mathrm{KNO}_{3}$ & 1.0 & \\
\hline & $\mathrm{K}_{2} \mathrm{HPO}_{4} \cdot 3 \mathrm{H}_{2} \mathrm{O}$ & 0.5 & \\
\hline & Agar & 15 & \\
\hline & $\mathrm{MgSO}_{4} \cdot 7 \mathrm{H}_{2} \mathrm{O}$ & 0.5 & \\
\hline & $\mathrm{NaCl}$ & 0.5 & \\
\hline & $\mathrm{FeSO}_{4} \cdot 7 \mathrm{H}_{2} \mathrm{O}$ & 0.01 & \\
\hline & Distilled water & & 1000 \\
\hline
\end{tabular}

The plates were inverted and incubated at $37^{\circ} \mathrm{C}$. Colonies were counted using an automatic colony counter (Interscience scan300) after two days for bacteria, three days for fungi and seven days for actinomycetes. The number of colonies per gram of fresh soil was then calculated.

\section{Fungal and bacterial diversity estimation}

DNA was extracted from soil microorganisms for PCR amplification of the internal transcribed spacer (ITS) sequence to estimate fungal diversity and the $16 \mathrm{~S}$ rDNA sequence to estimate bacterial diversity.

\section{Extraction of DNA}

The Fast DNA Spin Kit for Soil Kit (MP Biomedicals Biomedical Co., Irvine, CA, USA) was used to extract total DNA from $500 \mathrm{mg}$ in a Lysing Matrix E tube with $978 \mathrm{ml}$ sodium phosphate buffer and $122 \mathrm{ml}$ MT buffer. The tube was placed in the Fastprep instrument and rotated at $6.0 \mathrm{~m} \mathrm{~s}^{-1}$ speed for $40 \mathrm{~s}$, centrifuged for $10 \mathrm{~min}$ at $14,000 \times g$. After centrifugation, the supernatant was transferred to $250 \mu \mathrm{L}$ [protein precipitation solution (PPS)] in a $2.0 \mathrm{~mL}$ catch tube which was centrifuged for $5 \mathrm{~min}$ at $14,000 \times g$ to precipitate the protein. The supernatant was transferred to a $15 \mathrm{ml}$ clean test tube with $1 \mathrm{ml}$ binding matrix solution and rotated for $2 \mathrm{~min}$, and then precipitated for $3 \mathrm{~min}$ to obtain the silica gel matrix. After removing the supernatant and adding SEWS-M and air-drying, DNA was extracted and stored in a refrigerator at $-20^{\circ} \mathrm{C}$.

\section{PCR amplification}

The extracted DNA was separated electrophoretically in $1 \%$ agarose to detect whether the extracted DNA was in accordance with the sequencing requirements. Before amplification of the target genes, a random bacterial and fungal DNA sample was selected to test whether the target gene was amplified and with a minimum number of cycles.

For bacteria, the $16 \mathrm{~S}$ V3-V4 region was amplified using primer pair 338F (ACTCCTACGGGAGGCAGC AG)/806R (GGACTACHVGGGTWTCTAAT), TransStart Fastpfu DNA polymerase (Beijing TransGen Biological Co., Beijing) with 30 ng DNA sample, $1 \mu \mathrm{L}$ forward primer $(5 \mu \mathrm{M}), 1 \mu \mathrm{L}$ reverse primer $(5 \mu \mathrm{M}), 3 \mu \mathrm{L}$ BSA $\left(2 \mathrm{ng} \mu \mathrm{L}^{-1}\right), 12.5 \mu \mathrm{L} 2 \times$ Taq PCR MasterMix and $7.5 \mu \mathrm{L} \mathrm{ddH_{2 }} \mathrm{O}$. Cycling conditions were $95{ }^{\circ} \mathrm{C}$ for $5 \mathrm{~min}$; 28 cycles of $95{ }^{\circ} \mathrm{C}$ for $45 \mathrm{~s}, 55^{\circ} \mathrm{C}$ for $45 \mathrm{~s}$ and extended at $72{ }^{\circ} \mathrm{C}$ for $45 \mathrm{~s} ; 10 \mathrm{~min}$ at $72{ }^{\circ} \mathrm{C}$. PCR amplification products (target genes) were preserved at $4{ }^{\circ} \mathrm{C}$ and sequenced as soon as possible.

For fungi, the ITS1-ITS2 region was amplified using primer pair ITS1-F (CTTGGTCATTTAGAGGAAGTAA)/ ITS2 (TGCGTTCTTCATCGATGC) and the same polymerase and PCR system used for bacteria, except 32 cycles were used. 


\section{DNA high-throughput sequencing}

After electrophoretic detection and quality control, the amplified fragments were used to construct a Miseq library using the NEBNext Ultr DNA Library Prep Kit for Illumina and the standard protocol. The amplified fragment and the expanded sublibrary were then sequenced using the Illumina MiSeq PE300 platform (Illumina, San Diego, CA, USA). The PE reads obtained were spliced according to the overlap relationship between PE reads, and the sequence quality was controlled and filtered. According to the barcode and primer information at both ends of the sequence, the effective sequence was distinguished, the sequence direction was corrected, and the optimized sequence was obtained by using software FLASH and Trimmomatic. These steps were carried out by the Allwegene Technology Company in Beijing.

\section{Statistical analyses}

We used Pearson correlation analysis to assess correlations between the severity of decay and each of the soil property indicators, and a one-sample $t$-test to analyze differences between soil fungal diversity in the root zone of decaying and healthy sample trees. Multiple linear regression was used to construct the optimum regression equation relating the severity of tree decay with soil microbial quantity indicators, which were the dependent and independent variables, respectively. Path analysis was employed to compare the effect of different kinds of soil microorganisms on tree decay. All statistical analyses were done using SPSS 22.0 (IBM Co., Armonk, NY, USA).

\section{Results}

\section{Tree trunk decay severity}

Decay changes wood properties and decreases its quality. Mass loss in the wood core is usually used as a true value of wood decay (Liu et al. 2015). The mass loss data for 10 sample trees is considered as decay severity (Table 2). The mass loss of the wood core $\mathrm{C} 2$ was 0 i.e., from a healthy tree. Cores R3 and S2 had the most severe decay with mass loss of $47.1 \%$ and $48.3 \%$, respectively.

\section{Soil chemical properties versus trunk decay severity of standing trees}

As the degree of decay increased for the sample trees, total $\mathrm{N}$ and $\mathrm{K}$ in the root zone soil rhizosphere gradually increased (Fig. 1a). Each was higher than the total $P$ which changed slightly as decay severity increased. Similarly, hydrolytic $\mathrm{N}$ and available $\mathrm{K}$ were higher than available $\mathrm{P}$ in the root zone soil and showed a slightly increasing trend (Fig. 1b). Thus, these elements were more abundant in the root soil around decaying standing trees than around healthy trees, and might be due to the their release from decaying litter and their incorporation into soil organic matter. In addition, there was more decaying litter under decaying trees. Reduced uptake of nutrients from the soil might also contribute to the increase in these elements.
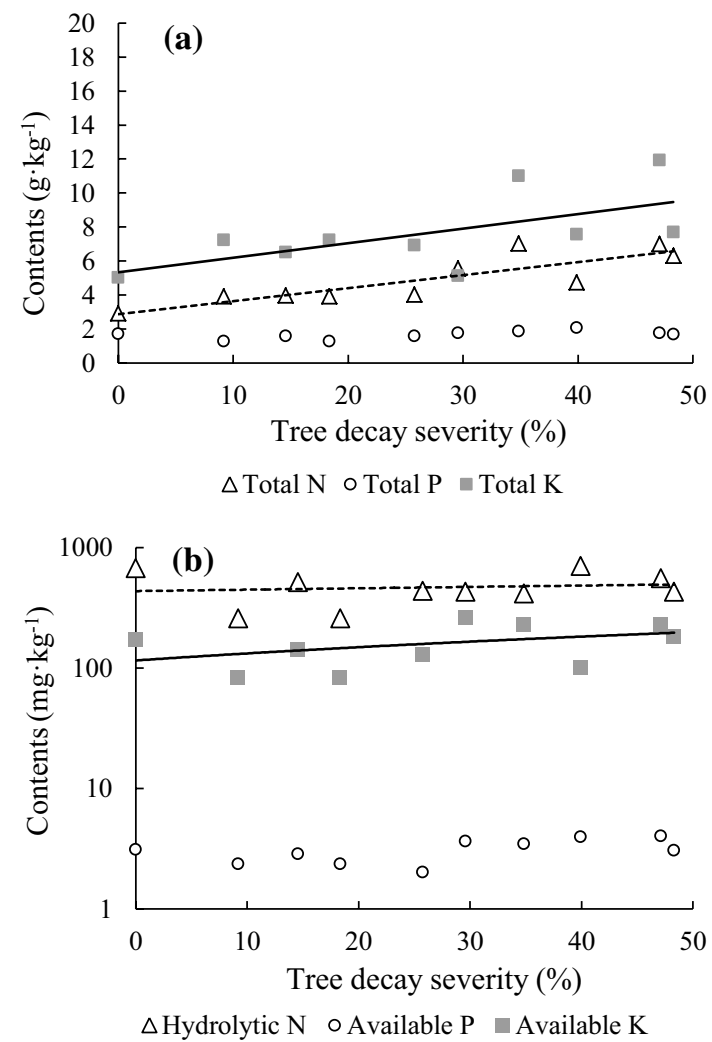

Fig. 1 Relation between tree decay severity and soil chemical properties
Table 2 Decay severity as percentage loss in mass in 10 wood cores from sample trees

\begin{tabular}{lllllllllll}
\hline Variable & A2 & B2 & C2 & D3 & E3 & F3 & G1 & H3 & R3 & S2 \\
\hline Decay severity (\%) & 14.56 & 18.35 & 0 & 9.18 & 29.57 & 39.90 & 34.84 & 25.76 & 47.11 & 48.30
\end{tabular}

Each core is coded with a letter for the tree and the core number; one healthy (C2) and nine decaying trees were analyzed 


\section{Soil microbial quantity versus trunk decay severity of standing trees}

The distribution of soil microorganisms around the roots of sample trees with different decay severities was: bacteria $>$ actinomycetes $>$ fungi, with the number of bacteria (BN) $10-10^{4}$ times higher than actinomycetes, and $10^{3}-10^{5}$ times higher than fungi (Fig. 2). Thus, bacteria were clearly the key contributors to soil microbial activity. As the severity of decay increased, the number of microbes of all microbial types increased gradually (Fig. 2), indicating decay severity might be closely related to the community of root soil microorganisms.

Multiple linear regression analysis was used to analyze the relationship between decay severity and root soil microbial abundance. The regression result is $y=-18.457+3$. $564 \times 10-4 \times 2+7.683 \times 10-5 \times 3\left(R^{2}=0.664, p=0.000\right)$, where $y$ is tree decay severity (Wood core WLR), $\times 2$ is the number of fungi (FN) and $\times 3$ is the number of actinomycetes (AN). The equation shows that decay severity was mainly related to the number of FN and AN in the soil.

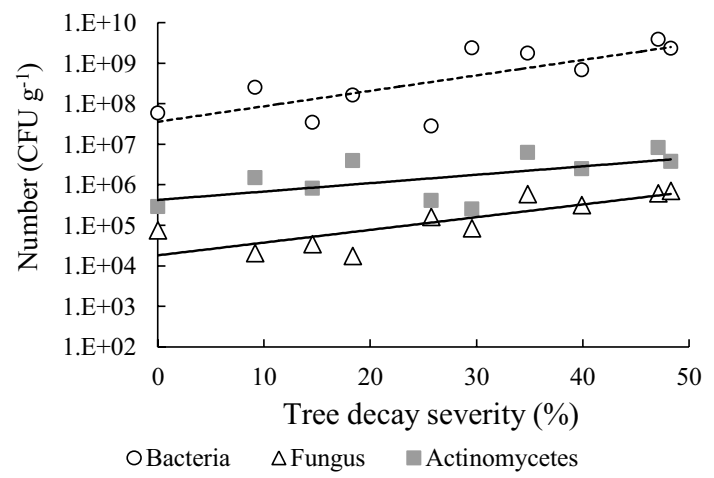

Fig. 2 Relation between tree decay severity and soil microbial quantity

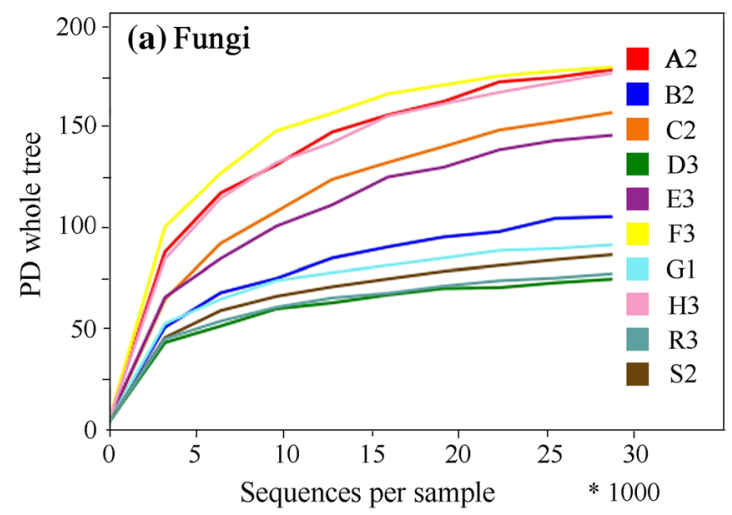

However, a low determination coefficient $\left(R^{2}=0.664\right)$ and a large residual factor $[\mathrm{e}=0.5(1-R)=0.336]$ were also found, which indicates that other factors might exist in addition to FN and AN.

In the path analysis to further study the effect of soil microorganisms on tree decay, the direct path coefficient (DPC, $P_{\text {iy }}$ ) between any independent variable $x_{\mathrm{i}}$ and dependent variable $y$ is the standard coefficient of the linear regression equation, and the indirect path coefficient (IPC, $P_{\text {xi-xj }}$ ) is the product of the Person correlation coefficient $\left(r_{i j}\right)$ and DPC $\left(P_{j y}\right)$ of any independent variable $x_{\mathrm{i}}$ to $y$. The DPCs of BN, FN and AN on decay severity was $-0.305,0.397$ and 0.413 , respectively, indicating that the direct effect of bacteria on decay severity was negative and not significant $(p=0.113)$, but the direct effects of fungi and actinomycetes on decay severity were positive.

Based on the Pearson correlation coefficient, the IPCs between soil microbe numbers and decay severity were calculated. The greatest negative IPC, -0.209 , was found between $\mathrm{BN}$ and $\mathrm{FN}$, indicating that $\mathrm{BN}$ could affect $\mathrm{FN}$ in the soil and then might indirectly inhibit tree decay. All other IPCs between soil microbes were positive; the greatest positive IPC, 0.211, was between AN and FN, which meant that soil AN could accelerate tree decay by affecting FN. The IPC between AN and BN was the smallest (0.117).

\section{Soil microbial diversity versus trunk decay severity of standing trees}

\section{Soil microbial species diversity}

$\alpha$-Diversity represents the richness and evenness of different species of microorganisms. PD_whole_tree curve and Rank_abundance curve were applied to characterize the $\alpha$-diversity of species (Figs. 3, 4).

PD_whole_tree is the sum of the branching lengths in the phylogenetic trees constructed using all groups in

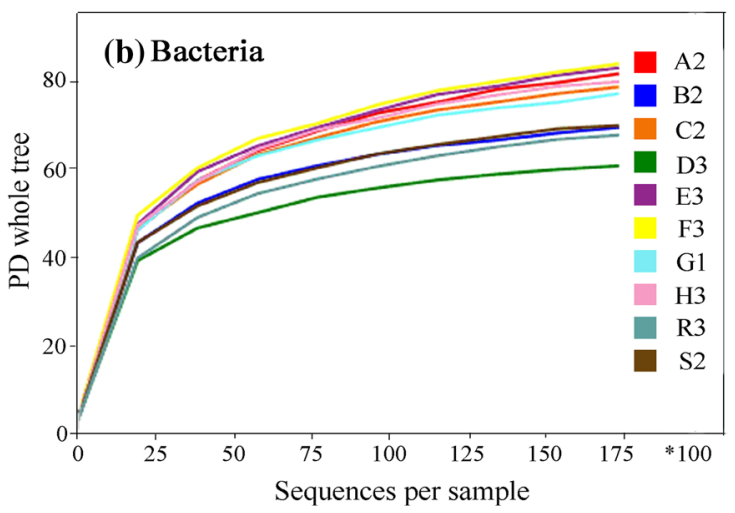

Fig. 3 Rarefaction measure PD_whole_tree curves for $\mathbf{a}$ fungi and $\mathbf{b}$ bacteria 
the sample (Goedert et al. 2015). The higher the PD_ whole_tree value, the greater the species richness in the sample. For both fungal and bacteria species, F3 was the most abundant (fungi: PD_whole_tree value $>175$; bacteria: > 80) and D3 was the lowest in species number and diversity.

For the Rank_abundance curve to analyze species diversity, the shape reflects the homogeneity of species composition. The slower the downward trend of the curve, the higher the uniformity of the species composition (Bates et al. 2013). For fungi and bacteria, the curve decreased rapidly and steeply, indicating that the dominant flora in the samples accounted for a higher proportion and the species distribution was not uniform (Fig. 4).

\section{Statistical analyses for relation between soil microbial diversity and tree decay}

$\alpha$-Diversity represents the richness of organisms in a particular region or ecosystem. The commonly used indices are the Chao1 index, PD_whole_tree index and Shannon index. In the Pearson correlation analysis of the relationship between decay severity of $P$. koraiensis and soil microbial $\alpha$-diversity, there was no significant correlation between fungal $\alpha$-diversity and decay severity. The same results were found for bacterial $\alpha$-diversity (Table 3 ).

One-sample $t$-test was employed to analyze the relation between fungal PD_whole_tree index and bacterial PD_whole_tree index; the results show that there was no significant difference between decay and healthy tree with a value in fungal diversity (2-tailed, $p=0.062$ ) and in bacterial diversity (2-tailed, $p=0.195$ ), shown in Table 4 .
Fig. 4 Rank_abundance curves of fungi and bacteria
Table 3 Pearson correlation analysis of microbial diversity and decay severity of sample trees

Table 4 One-sample $t$-test of PD_whole_tree for bacteria
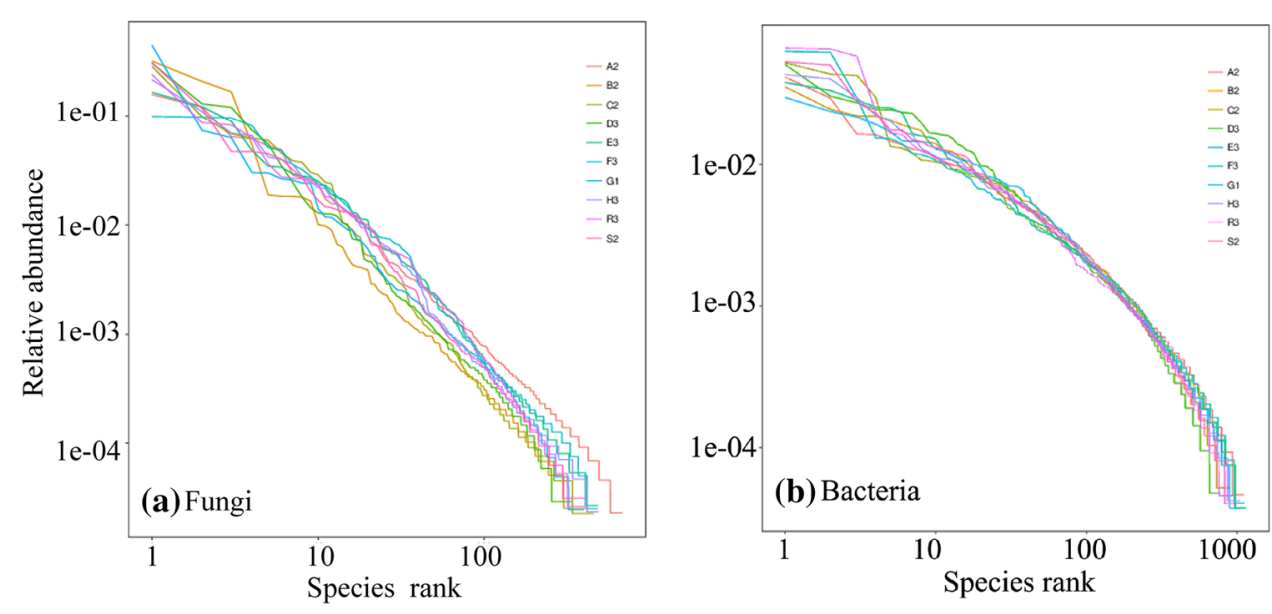

\begin{tabular}{|c|c|c|c|c|c|c|}
\hline \multirow[t]{2}{*}{ Microbial group } & \multicolumn{2}{|l|}{ Chao1 } & \multicolumn{2}{|l|}{ Shannon } & \multicolumn{2}{|c|}{ PD_whole_tree } \\
\hline & $R$ & $p$ & $R$ & $p$ & $R$ & $p$ \\
\hline Fungi & -0.149 & 0.682 & 0.285 & 0.425 & -0.279 & 0.435 \\
\hline Bacteria & 0.019 & 0.958 & -0.250 & 0.486 & 0.010 & 0.977 \\
\hline
\end{tabular}

PD is phylogenetic diversity. PD_whole_tree is the sum of the branching lengths in the phylogenetic trees constructed using all groups in the sample

\begin{tabular}{lrllclll}
\hline Microbe group & $t$ & df & $p$ (2-tailed) & Mean difference & SE & \multicolumn{2}{l}{$\begin{array}{l}\text { 95\% confidence } \\
\text { interval }\end{array}$} \\
\cline { 3 - 7 } & & & & & & Lower & Upper \\
\hline Fungi & 157.269 & 8 & 0.062 & -33.176 & -2.173 & -68.390 & 2.038 \\
Bacteria & 78.732 & 8 & 0.195 & -3.838 & -1.413 & -10.102 & 2.426 \\
\hline
\end{tabular}

PD is phylogenetic diversity; PD_whole_tree the sum of the branching lengths in the phylogenetic trees constructed using all groups in the sample; SE is standard error 
Fig. 5 The unifrac_distance graph for species in various fungal phyla, Cercozoa, and others
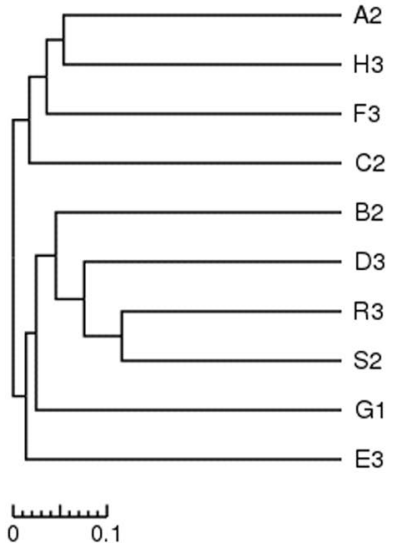

\section{Identification and analysis of dominant microbial species}

Species richness, the number of individuals of each species in the samples, is obtained from the operational taxonomic units (OTUs), while the abundance of OTUs can be calculated from the number of sequences in OTU. Through high-throughput sequencing, seven known phyla and 203 known species were found in soil samples from the rhizosphere around the roots. Among all species, 21 had a relative abundance $>1 \%$. The top three fungal phyla were Zygomycota (6.3\%), Ascomycota (35.4\%) and Basidiomycota

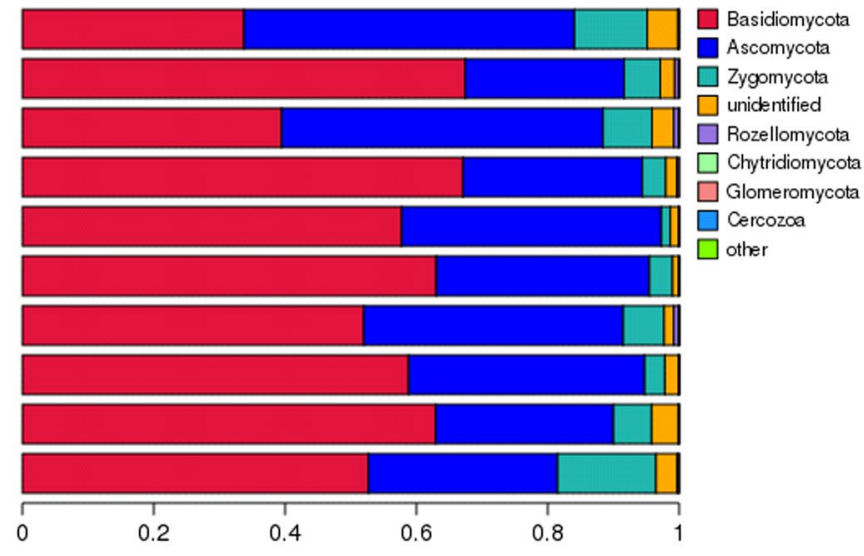

(55.4\%), accounting for $97.1 \%$ of all fungi (Fig. 5). The relative abundance of agaricomycetes (Basidiomycota), the primary group associated with wood decay (Shang 2008), was $46.6 \%$, but further statistical analysis showed that their abundance was not correlated with decay severity of standing trees $(R=-0.229, p=0.525)$. For other species, some are known soil inhabitants (Cryptococcus_podzolicus; Liu 2016), others ectomycorrhizal fungi (Inocybe_maculata; Larsson et al. 2009), and other pathogenic fungi (Nectria_ ramulariae). But their distribution in 10 samples was not correlated with decay severity.

Table 5 Fungal species with > $1 \%$ abundance and their relative abundance in 10 core samples (C2 is from a healthy tree)

\begin{tabular}{|c|c|c|c|c|c|c|c|c|c|c|}
\hline Species & $\mathrm{C} 2$ & D3 & A2 & B2 & H3 & E3 & G1 & F3 & R3 & $\mathrm{S} 2$ \\
\hline Amanita_argentea & 28.5066 & 0.0467 & 0.0643 & 0.0712 & 0.0000 & 0.0000 & 0.0000 & 0.0000 & 0.0026 & 0.0031 \\
\hline Tricholoma_terreum & 4.5484 & 0.0146 & 0.0253 & 0.0356 & 0.1339 & 0.0027 & 0.0000 & 0.0853 & 24.0095 & 0.1411 \\
\hline Russula_aff_integra_r_03014 & 3.8724 & 0.0263 & 0.0298 & 0.0229 & 0.0000 & 0.0000 & 0.0000 & 0.0000 & 0.0026 & 0.0000 \\
\hline Nectria_ramulariae & 3.7250 & 0.0963 & 2.8694 & 1.8280 & 3.9643 & 1.1080 & 0.7216 & 9.7524 & 2.4210 & 0.5017 \\
\hline Cryptococcus_podzolicus & 2.8811 & 1.0683 & 4.8826 & 0.6686 & 2.2089 & 2.8020 & 2.4939 & 2.3609 & 1.1855 & 0.9125 \\
\hline Tylospora_fibrillosa & 0.0363 & 11.9968 & 0.0321 & 0.0966 & 0.0047 & 0.0054 & 0.0000 & 0.0000 & 0.0000 & 0.0031 \\
\hline Russula_aff_turci_r_04101 & 0.0295 & 5.5226 & 0.0207 & 0.0254 & 0.0000 & 8.9306 & 0.0933 & 0.0000 & 0.0026 & 0.0000 \\
\hline Piloderma_byssinum & 0.0295 & 3.4765 & 0.0161 & 0.0381 & 0.0000 & 0.0000 & 0.0000 & 0.0000 & 0.0026 & 0.0000 \\
\hline Amphinema_sp_6_UK_2011 & 0.0023 & 1.1997 & 0.0023 & 0.0051 & 0.0000 & 0.0000 & 0.0000 & 0.0000 & 0.0000 & 0.0031 \\
\hline Cryptococcus_terricola & 0.3630 & 1.0129 & 1.4209 & 0.0458 & 0.3924 & 0.7654 & 1.3991 & 0.5645 & 0.3030 & 1.3233 \\
\hline Mortierella_humilis & 0.3766 & 0.4145 & 2.5572 & 0.4119 & 1.2971 & 4.5549 & 1.3157 & 2.9154 & 1.1960 & 1.4613 \\
\hline Mortierella_camargensis & 0.2858 & 0.1255 & 2.6467 & 0.4500 & 1.3230 & 1.7155 & 0.2626 & 2.0523 & 2.5843 & 0.1662 \\
\hline Russula_viscida & 0.1066 & 0.1080 & 12.0309 & 0.1297 & 0.0047 & 0.0000 & 0.0000 & 0.0000 & 0.0026 & 0.0000 \\
\hline Inocybe_maculata & 0.1089 & 0.0671 & 0.0803 & 32.0316 & 0.0047 & 0.0000 & 0.0000 & 0.0075 & 0.0053 & 0.0031 \\
\hline Inocybe_glabrodisca & 0.0408 & 0.0292 & 0.0803 & 20.7917 & 0.0070 & 0.0000 & 0.0000 & 0.0000 & 0.0000 & 0.0063 \\
\hline Inocybe_rimosoides & 0.3108 & 0.0029 & 0.0000 & 0.0025 & 6.5680 & 0.0000 & 0.0000 & 0.0301 & 0.0342 & 0.0125 \\
\hline Humicola_nigrescens & 0.0181 & 0.0175 & 0.8080 & 0.0559 & 0.0775 & 3.4550 & 0.6063 & 0.6323 & 0.5796 & 0.1098 \\
\hline Tomentella_stuposa & 0.0045 & 0.5517 & 0.0069 & 0.0025 & 0.0094 & 0.0107 & 2.4153 & 0.0201 & 0.0000 & 0.0125 \\
\hline Lactarius_flexиosus & 0.0000 & 0.0029 & 0.0000 & 0.0000 & 0.0235 & 0.0000 & 0.0000 & 3.5678 & 0.0184 & 0.0094 \\
\hline Thelephora_palmata & 0.0000 & 0.0000 & 0.0390 & 0.0000 & 0.0047 & 0.0000 & 0.0000 & 0.0050 & 1.7940 & 0.0063 \\
\hline Oidiodendron_chlamydosporicum & 0.2064 & 0.0701 & 0.3581 & 0.0127 & 0.3830 & 0.8136 & 0.1325 & 0.2534 & 0.6349 & 1.4738 \\
\hline
\end{tabular}


The relationship between relative abundance of the 203 species and the decay severity of $P$. koraiensis was further analyzed. Of all species, the number with more than $1 \%$ of relative abundance was 21, including Amanita_argentea, Tricholoma_terreum, Russula_viscida, Russula_aff_ integra_r_03014. Their relative abundance in 10 samples was shown in Table 5.

In similar analyses for bacteria, species with relative abundance $>1 \%$ included Nitrospirae (1.78\%), Bacteroidetes (4.32\%), Gemmatimonadetes (4.34\%), Chloroflexi (5.16\%), Verrucomicrobia (7.36\%), Actinobacteria (10.82\%), Acidobacteria (30.03\%) and Proteobacteria (33.34\%), accounting for $97.15 \%$ of all bacteria. The relative abundance of different bacterial species was not correlated with various decay severities.

\section{Conclusions}

Higher levels of N, P, and K, especially total $\mathrm{N}$ and $\mathrm{K}$, were found in the rhizosphere from decaying standing trees than from healthy standing trees.

As tree decay severity increased, the quantity of microorganisms in the soil around the tree roots increased gradually. Statistical analysis showed that decay severity was related to the number of fungi and actinomycetes. Soil bacteria may indirectly inhibit tree decay by affecting the number of fungi in the soil.

High-throughput sequencing and statistical analysis showed that decay severity of Pinus koraiensis was not correlated with soil microbial (fungal and bacterial) diversity.

Open Access This article is licensed under a Creative Commons Attribution 4.0 International License, which permits use, sharing, adaptation, distribution and reproduction in any medium or format, as long as you give appropriate credit to the original author(s) and the source, provide a link to the Creative Commons licence, and indicate if changes were made. The images or other third party material in this article are included in the article's Creative Commons licence, unless indicated otherwise in a credit line to the material. If material is not included in the article's Creative Commons licence and your intended use is not permitted by statutory regulation or exceeds the permitted use, you will need to obtain permission directly from the copyright holder. To view a copy of this licence, visit http://creativecommons.org/licenses/by/4.0/.

\section{References}

Bates ST, Clemente JC, Flores GE, Walters WA, Parfrey LW, NoahFiereret PK (2013) Global biogeography of highly diverse protistan communities in soil. ISME J 7:652-659
Bednarz JC, Huss MJ, Benson TJ, Varland DE (2013) The efficacy of fungal inoculation of live trees to create wood decay and wildlifeuse trees in managed forests of western Washington. USA For Ecol Manage 307(6):186-195

Cai ZC, Huang XQ (2016) Soil-borne pathogens should not be ignored by soil science. Acta Pedol Sin 53(2):305-310

Chen SC (1959) A preliminary study on the spread of the hidden rot of Abies in southwest forest area. Scientia Silvae Sinicae 5(1):55-67

Goedert JJ, Jones G, Hua X, Xu X, Yu GQ, Flores R, Falk RT, Gail MH, Shi JX (2015) Investigation of the association between the fecal microbiota and breast cancer in postmenopausal women: A population-based case-control pilot study. JNCI J Natl Cancer Inst. https://doi.org/10.1093/jnci/djv147

Hietala AM, Nagy NE, Burchardt EC, Solheim H (2016) Interactions between soil $\mathrm{pH}$, wood heavy metal content and fungal decay at Norway spruce stands. Appl Soil Ecol 107:237-243

Hu YL, Wang SL, Zeng DH (2006) Effects of single Chinese fir and mixed leaf litters on soil chemical, microbial properties and soil enzyme activities. Plant Soil 282(1-2):379-386

Larsson E, Ryberg M, Moreau PA, Delcuse MA, Jacobsson S (2009) Taxonomy and evolutionary relationships within species of section Rimosae (Inocybe) based on ITS LSU and mtSSU sequence data. Persoonia 23(1):86-98

Li XY, Dong SB, Wang JN (2014) Occurrence and control of root rot of Pinus koraiensis. China Sci Technol Inf 12:164-164

Liu HT (2016) Plylogeny and renaming of Cryptococcus podzolicus are related strains. Guizhou Medical University, Guizhou

Liu ZX, Wang LH, Bao ZY, Sun TY (2015) Quantitative detection of internal decay degree in Korean pine standing. J Northeast For Univ 43(6):89-92

Lv J, Qu SM (2010) Variety of economic value of development utilize of Korean pine. For Investig Des 2:70-71

Martiny JBH, Bohannan BJM, Brown JH, Colwell RK, Fuhrman JA, Green JL, Horner-Devine MC, Kane M, Krumins JA, Kuske CR, Morin PJ, Naeem S, Øvreås L, Reysenbach AL, Smith VH, Staley JT (2006) Microbial biogeography: putting microorganisms on the map. Nat Rev Microbiol 4(2):102-112

Pietri JCA, Brookes PC (2008) Relationships between soil pH and microbial properties in a UK arable soil. Soil Biol Biochem 40(7):1856-1861

Shang B (2008) The wood rotting fungi and soil fungi of the two dominate forest types in Songshan. Beijing Forestry University, Beijing, pp 10-15

Shortle WC, Dudzik KR (2012) Wood decay in living and dead trees: a pictorial overview. General Technical Report NRS-97. United States Department of Agriculture Forest Service 2012. https://pdfs.seman ticscholar.org/57c1/79af908ff583353e2bd5c6b64c8012753af5.pdf

Sun TY, Wang LH, Xu HD, Bao ZY (2015) Effect of soil physicalchemical properties on the decay of standing Pinus koraiensis in Xiaoxing' an Mountains, northeast China. J For Res 26(4):859-865

Wang YT, Xu HD, Wang LH (2015) Rate of Korean pine standing trees in natural forests in Lesser Xing' an Mountains. J Beijing For Univ 37(8):97-104

Xu HD, Di YN, Cao YJ, Wang LH, Wang HB (2019) Relationship between cultural soil microbial quantity and Butt Decay Degree of Pinus koraiensis Standing Tree. J Northeast For Univ 47(1):52-55

Publisher's Note Springer Nature remains neutral with regard to jurisdictional claims in published maps and institutional affiliations. 